\title{
Bioavailability and toxicity variation of benzo[a]pyrene in three soil-wheat systems: Indicators of soil quality
}

\author{
Yong Teng ${ }^{1}$ and Qixing Zhou ${ }^{1}$ \\ ${ }^{1}$ Nankai University
}

December 10, 2020

\begin{abstract}
Benzo[a]pyrene (B[a]P) as a representative polycyclic aromatic hydrocarbons is concerned by global scientists in various fields, but its biological and biochemical actions in soil-wheat systems are still rarely reported. The B[a]P as a ubiquitous soil pollutant possesses varied contents in real environment, and herein was studied in systems of soil and wheat to obtain relative results to reveal their variations in different systems. Its bioavailability (extractability and bioaccumulation) and basic biological toxicity were tested based on three typical soil types (red, black, and brown) in China and spiked amounts (0.1, 1, and 10 mg/kg) with several orders of magnitude. Results showed that B[a]P concentrations in soil-wheat systems extracted by HPCD were insignificantly $(\mathrm{p}>0.05)$ higher than Tenax-TA, and varied with soil types and spiked concentrations. Besides, the root and shoot length were mostly inhibited, in a range of $-21.85 \%-26.35 \%$ and $-0.48 \%-54.85 \%$, respectively, by B[a]P in different soil types and increased with its increasing concentration. Comparatively, higher bioconcentration factor and translocation factor values were observed under lower group in red soil-wheat systems, and higher spiked groups in black and brown soil-wheat systems. Moreover, inhibitive effects posed by B[a]P were mainly targeted at wheat shoots in these soils. The simultaneous studies provided a comparable knowledge of $\mathrm{B}[\mathrm{a}] \mathrm{P}$ in ecosystems of different soil types combined with different plant species due to lots of variations, further to serve for contaminated soil remediation and sustainable agricultural management.
\end{abstract}

\section{Hosted file}

manuscript.pdf available at https://authorea.com/users/382122/articles/498085bioavailability-and-toxicity-variation-of-benzo-a-pyrene-in-three-soil-wheat-systemsindicators-of-soil-quality 

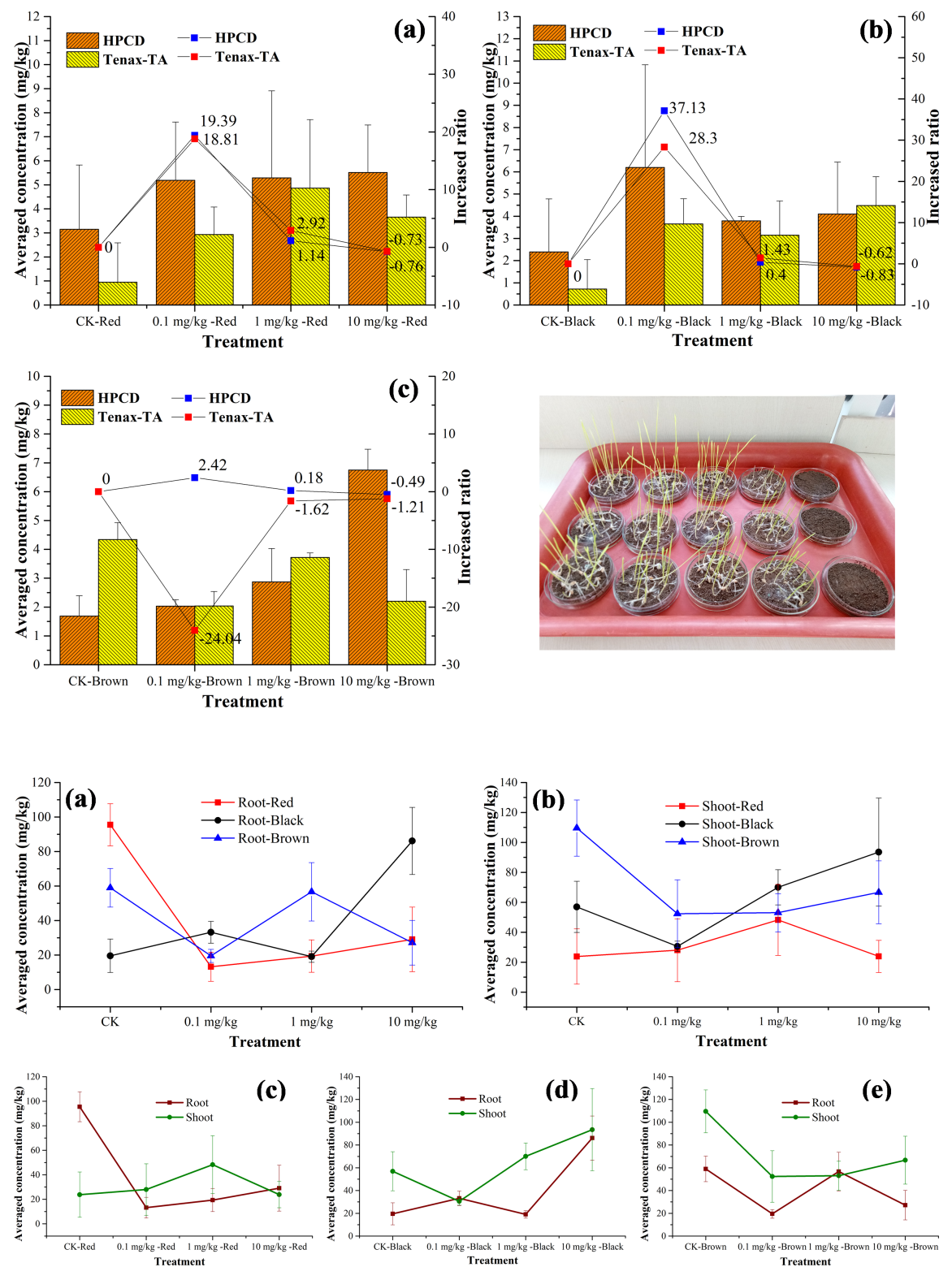


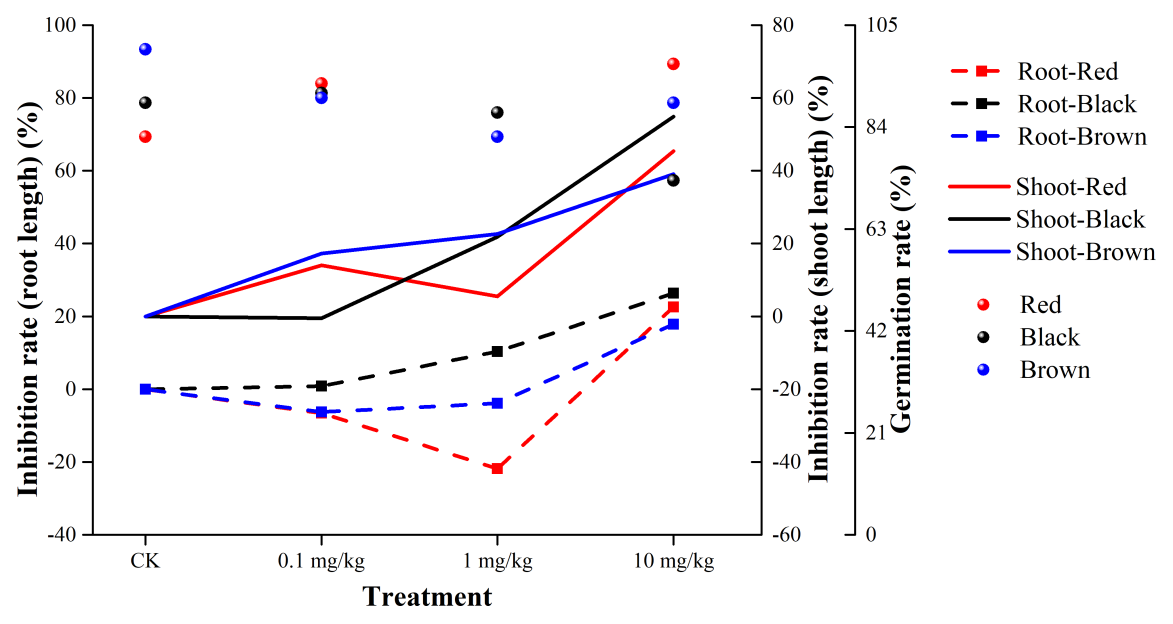

